\title{
The Maintenance of the Relative Humidity of the Subtropical Free Troposphere
}

\author{
AleXANDRE COUHERT AND TAPIO SCHNEIDER \\ California Institute of Technology, Pasadena, California \\ JUILIN Li AND DUANE E. WALISER \\ Jet Propulsion Laboratory, California Institute of Technology, Pasadena, California \\ ADRIAN M. TOMPKINS* \\ European Centre for Medium-Range Weather Forecasts, Reading, United Kingdom
}

(Manuscript received 1 December 2008, in final form 3 August 2009)

\begin{abstract}
The relative importance of different processes in the water vapor balance of the troposphere is assessed, using high-resolution hindcast data from the ECMWF Integrated Forecast System (IFS) for DecemberFebruary 1998/99 interpolated to isentropic coordinates. The focus is on elucidating the processes that maintain the relative humidity of the subtropical free troposphere. The dominant drying process in the subtropical free troposphere is cross-isentropic subsidence driven by radiative cooling. In some subtropical regions [e.g., over continents in the Southern (summer) Hemisphere and over western portions of ocean basins in the Northern (winter) Hemisphere], drying by radiative subsidence is partially offset or overcompensated by moistening by cross-isentropic dynamic transport of water vapor from the surface upward (e.g., in convection). Any resultant net drying or moistening of the subtropical free troposphere by crossisentropic motions is regionally primarily balanced by isentropic mean and eddy transport of water vapor from moister into drier regions. Isentropic transport redistributes water vapor within the subtropics and moderates relative humidity contrasts; however, it does not consistently lead to a substantial net import or export of water vapor into or out of the subtropics.
\end{abstract}

\section{Introduction}

Water vapor plays an essential role in earth's climate as a mediator of radiative feedbacks in the response of the climate system to perturbations. In particular, the infrared water vapor feedback is strongest in the free troposphere (Held and Soden 2000). Since the infrared radiative forcing associated with changes in atmospheric water vapor concentration scales approximately with relative rather than absolute concentration changes, the subtropical free troposphere has the potential to be

\footnotetext{
* Current affiliation: International Centre for Theoretical Physics, Trieste, Italy.
}

Corresponding author address: Tapio Schneider, California Institute of Technology, Mail Code 100-23, 1200 E. California Blvd., Pasadena, CA 91125.

E-mail: tapio@caltech.edu a locus of pivotal climate feedbacks, as its relative dryness in principle allows large relative changes in water vapor concentration (Pierrehumbert 1999). It is therefore imperative to understand the mechanisms maintaining the relative humidity of the subtropical free troposphere and how they may change as the climate changes.

Near the relative humidity minima in the subtropical free troposphere, located at a pressure of $\sim 500 \mathrm{hPa}$ in the descending branches of the Hadley circulation, the specific humidity $\left(\sim 10^{-3}\right)$ is about two orders of magnitude greater than near the tropopause $\left(\sim 10^{-5}\right)$. This shows that the air in the descending branches of the Hadley circulation is moistened; its specific humidity is not conserved following the mean subsidence and would be much lower if mean subsidence alone controlled it (Pierrehumbert 1999). Different processes have been suggested that may moisten the subsiding air: evaporation or sublimation of condensate in the vicinity of deep convective clouds (Sun 
and Lindzen 1993), cross-isentropic vertical mixing in moist convection (Yang and Pierrehumbert 1994), and approximately isentropic meridional advection of moist air from tropical regions by large-scale eddies (Emanuel and Pierrehumbert 1995; Salathé and Hartman 1997; Pierrehumbert 1998; Pierrehumbert and Roca 1998; Ryoo et al. 2009), the latter potentially coupled with cross-isentropic vertical mixing in isolated convective clouds (Sherwood 1996a). The diversity of mechanisms proposed reflects the uncertainty surrounding the nature of the dominant moistening process.

Analyzing the water vapor balance in isentropic coordinates using the European Centre for MediumRange Weather Forecasts (ECMWF) Re-Analysis (ERA-40) data, Schneider et al. (2006) showed that, in the zonal mean in all seasons, the dominant moistening process balancing the drying of the subtropical free troposphere by mean subsidence is convergence of crossisentropic turbulent fluxes that transport water vapor from the surface upward; evaporation/sublimation of condensate may also play a role. However, the nature and zonal localization of the dynamical processes involved in this moistening is unclear. In the zonal mean, isentropic eddy fluxes transport water vapor meridionally from the deep tropics into the extratropics, without exhibiting sufficient convergence in the subtropical free troposphere to balance the drying by cross-isentropic mean subsidence, particularly not in winter in the descending branches of the strong cross-equatorial Hadley cells (Schneider et al. 2006). But locally they may lead to strong drying or moistening in the subtropical free troposphere-tendencies that may just happen to cancel in the zonal mean. To improve our understanding of how the relative humidity of the subtropical free troposphere is maintained and may vary with climate, it is important to disentangle the various processes that may play a role and to do so in a way that resolves zonal variations, which may be expected to be large in the subtropics. Here we use improved higher-resolution data from a more recent version of the ECMWF Integrated Forecast System (IFS) for one boreal winter season to (i) confirm the findings of Schneider et al. (2006) for the zonal mean; (ii) analyze which processes, according to the IFS data, are responsible for the moistening of the subtropical free troposphere; and (iii) analyze zonal asymmetries in the water vapor balance of the free troposphere.

Section 2 introduces the theoretical framework of our analysis, the water vapor balance in isentropic coordinates. Section 3 describes the data sources and processing methods. Section 4 analyzes the relative importance of different processes in the water vapor balance in isentropic coordinates. Section 5 summarizes the conclusions. The appendix contains details of the data processing methods.

\section{Water vapor balance in isentropic coordinates}

\section{a. Instantaneous balance equation}

In isentropic coordinates, the water vapor balance can be written as

$$
\partial_{t}\left(\rho_{\theta} q\right)+\nabla_{\theta} \cdot\left(\rho_{\theta} \mathbf{v} q\right)+\partial_{\theta}\left(\rho_{\theta} Q q\right)=\rho_{\theta} S,
$$

where $\rho_{\theta}=-g^{-1} \partial_{\theta} p \mathcal{H}\left(\theta-\theta_{s}\right)$ is the isentropic density; $q$ is the specific humidity; $\mathbf{v}=(u, v)$ is the horizontal velocity; $\nabla_{\theta} \cdot(\cdot)$ is the divergence along isentropes; $Q=$ $D \theta / D t$ is the diabatic heating rate; and $\theta=T\left(p_{0} / p\right)^{\kappa}$ is the dry potential temperature with temperature $T$, adiabatic exponent $\kappa=R / c_{p}$, and reference pressure $p_{0}=$ $10^{5} \mathrm{~Pa}$. We neglect the small modification of the adiabatic exponent by water vapor (it amounts to less than $0.2 \%$ in the free troposphere). The Heaviside step function $\mathcal{H}(\cdot)$ in the isentropic density represents Lorenz's (1955) convention of setting the isentropic density to zero on isentropes with potential temperature $\theta$ less than the instantaneous surface potential temperature $\theta_{s}=$ $\theta_{s}(x, y, t)$. This convention ensures that the balance equation (1) holds on isentropes both above the surface $\left(\theta \geq \theta_{s}\right)$ and "inside" the surface $\left(\theta<\theta_{s}\right)$, where it reduces to the trivial statement $0=0$ (cf. Schneider 2005).

We take the flow fields on the left-hand side of the water vapor balance (1) to represent fields on the grid scale of the meteorological forecast system whose data we use. The water vapor source

$$
S=\frac{D q}{D t}=S_{g}+S_{c}+S_{t}
$$

then consists of contributions owing to evaporation/ sublimation and condensation on the grid scale $\left(S_{g}=\right.$ $e-c$, with rates of evaporation/sublimation $e$ and condensation $c$ per unit mass), to parameterized subgridscale moist convection $\left(S_{c}\right)$, and to other parameterized subgrid-scale turbulence $\left(S_{t}\right)$. That is, $Q_{2}=-L S$, with latent heat of vaporization/sublimation $L$, is Yanai's (1973) apparent moisture sink, which is often considered in studies of moist convection. Similarly, the diabatic heating rate

$$
Q=\frac{D \theta}{D t}=Q_{R}+Q_{L}+Q_{c}+Q_{t}
$$

consists of contributions owing to radiative heating $\left(Q_{R}\right)$, to latent heat release in grid-scale condensation minus cooling associated with evaporation/sublimation of condensate $\left(Q_{L}\right)$, to parameterized subgrid-scale moist convection $\left(Q_{c}\right)$, and to other parameterized subgrid-scale turbulence $\left(Q_{t}\right)$. That is, $Q_{1}=c_{p}(T / \theta) Q$ is Yanai's (1973) apparent heat source. Thus, some subgrid-scale processes, 
such as moist convection, contribute to fields on both the left-hand side and the right-hand side of the water balance (1): on the left through their contribution to the diabatic heating rate (the vertical velocity in isentropic coordinates), and on the right through their contribution to the water vapor source. For moist convection, for example, the diabatic heating rate $Q_{c}$ is the net heating rate on the grid scale that results from aggregating subgrid-scale convective updrafts and downdrafts, and the water vapor source $S_{c}$ is the net on the grid scale that results from aggregating subgrid-scale condensation and evaporation/sublimation of condensate.

\section{b. Mean balance equation}

Following the conventions in Schneider et al. (2006), we consider a mean water vapor balance

$$
\partial_{t}\left(\bar{\rho}_{\theta} \bar{q}^{*}\right)+\nabla_{\theta} \cdot\left(\bar{\rho}_{\theta} \overline{\mathbf{v}}^{*}\right)+\partial_{\theta}\left(\bar{\rho}_{\theta} \overline{Q q}^{*}\right)=\bar{\rho}_{\theta} \bar{S}^{*}
$$

where $\overline{(\cdot)}{ }^{*}=\overline{\left(\rho_{\theta} \cdot\right)} / \bar{\rho}_{\theta}$ denotes the mass-weighted mean associated with the temporal or temporal and zonal mean $\overline{(\cdot)}$. Decomposing flux terms into contributions associated with mean circulations and with fluctuations $(\cdot)^{\prime}=$ $(\cdot)-\overline{(\cdot)}^{*}$ about the mass-weighted isentropic mean, the mean water vapor balance (4) becomes

$$
\begin{aligned}
& \partial_{t}\left(\bar{\rho}_{\theta} \bar{q}^{*}\right)+\nabla_{\theta} \cdot\left(\bar{\rho}_{\theta} \overline{\mathbf{v}}^{*} \bar{q}^{*}\right)+\nabla_{\theta} \cdot\left(\bar{\rho}_{\theta} \overline{\mathbf{v}^{\prime} q^{\prime}}\right)+\partial_{\theta}\left(\bar{\rho}_{\theta} \bar{Q}^{*} \bar{q}^{*}\right) \\
& \quad=\bar{\rho}_{\theta} \bar{S}^{*}-\partial_{\theta}\left(\bar{\rho}_{\theta} \overline{Q^{\prime} q^{\prime}}\right) .
\end{aligned}
$$

Schneider et al. (2006) considered a temporally and zonally averaged water vapor balance (5) and could only determine the sum of the terms on the right-hand side as a residual. Here we focus on an only temporally averaged balance and are able to determine individual components of the terms on the right-hand side from the IFS data.

With terms determined from the IFS data, the lefthand side of the mean water vapor balance (5) is not necessarily exactly equal to the right-hand side. A nonzero residual - the difference between the left-hand and right-hand side - can arise for several reasons. For example, the data assimilation process can add or remove water vapor from the IFS model atmosphere and thus can lead to a lack of closure of the mean balance (5) within the IFS framework (e.g., Andersson et al. 2005); and interpolation and approximation errors in our processing of the IFS data can also lead to a lack of closure. We use the residual to check that our inferences about the dominant processes in the mean water vapor balance (5) are robust, at least within the IFS framework, that is, that the dominant terms are sufficiently large compared with the residual.

\section{Data and processing methods}

\section{a. Hindcast data}

We analyzed IFS hindcasts made with the cycle $31 \mathrm{r} 1$ forecast system operational on 12 September 2006 and based on reanalyses of observational data by fourdimensional variational data assimilation (Courtier et al. 1994; ECMWF 2007). The underlying meteorological model has 60 vertical levels up to $\sim 70 \mathrm{~km}$ altitude and horizontal spectral resolution T511 (corresponding to a horizontal resolution of $\sim 40 \mathrm{~km}$ ). We bilinearly interpolated daily data from the model grid to a $1^{\circ} \times 1^{\circ}$ regular latitude-longitude grid, on which we interpolated them, in each atmospheric column, to isentropic coordinates to calculate mean values at constant potential temperature (see the appendix for details).

The IFS data used represent an improvement over the ERA-40 data in several respects. The ERA-40 data are based on an earlier version of IFS (a modified version of that operational in June 2001), using three-dimensional variational data assimilation and a model with the lower horizontal spectral resolution T159 (corresponding to a horizontal resolution of $\sim 125 \mathrm{~km}$ ) (Uppala et al. 2005). Improvements in the IFS data come from the use of four-dimensional variational data assimilation with a 12 -h assimilation period, in place of the three-dimensional variational data assimilation with a 6 -h assimilation period used in ERA-40. This leads to better use of existing data and allows the assimilation of a wider range of satellite data (e.g., Hólm et al. 2002; Andersson et al. 2005, 2007). Additional improvements in the IFS data come from improvements in the model representation of subgrid-scale processes such as radiation, convection, and cloud processes (Tompkins et al. 2004). For example, the implementation of a new cloud physics parameterization that allows clear-sky ice supersaturation to occur led to a significant improvement in the representation of the hydrologic cycle, particularly in the upper troposphere (Tompkins et al. 2007; Waliser et al. 2009).

We focus on December-February (DJF) 1998/99, a season for which IFS data including subgrid-scale fields were available to us and that exhibits pronounced subtropical relative humidity minima, particularly one in the Northern Hemisphere. The IFS fields used are 24-h hindcasts starting at 1200 UTC of a given day. Some hindcast fields were available as instantaneous values at 12-h intervals after hindcast initialization, others as mean fields integrated over the 24 -h period after hindcast initialization. The instantaneous hindcast fields are the horizontal velocity $(\mathbf{v})$, temperature $(T)$, surface pressure 
$\left(p_{s}\right)$, and specific humidity $(q)$, and we used the mean of the 12- and 24-h instantaneous values to obtain fields approximately commensurate with 24 -h mean fields. The 24-h mean fields are those associated with parameterized processes: grid-scale condensation and evaporation/ sublimation $\left(Q_{L}\right.$ and $\left.S_{g}\right)$, subgrid-scale moist convection $\left(Q_{c}\right.$ and $\left.S_{c}\right)$, subgrid-scale turbulence $\left(Q_{t}\right.$ and $\left.S_{t}\right)$, and radiative heating $\left(Q_{R}\right)$. The various diabatic heating and water vapor source terms were added to obtain the total diabatic heating rate $Q$ and water vapor source $S$.

The physical processes captured by IFS that contribute to the diabatic heating rate and the water vapor source are described in detail in ECMWF (2007). The condensation and evaporation/sublimation of water on the grid scale are represented by $Q_{L}$ and $S_{g}$; they are parameterized by Tiedtke's (1993) scheme, which also advects cloud condensate, so that the evaporating/sublimating condensate in one grid box may have originated in another. Deep, shallow, and midlevel convection and the evaporation/sublimation of convective precipitation, parameterized by Tiedtke's (1989) bulk mass flux scheme, are represented by $Q_{c}$ and $S_{c}$. Turbulent mixing and transport of heat and water vapor in the planetary boundary layer, parameterized by an eddy diffusivity/mass flux scheme, are represented by $Q_{t}$ and $S_{t}$. Our inferences about the relative importance of different subgrid-scale processes in the water vapor balance hinge on the adequacy of the parameterizations in the IFS model.

\section{b. Saturation vapor pressure and relative humidity}

To estimate the relative humidity $H=e / e_{s}$, with water vapor pressure $e$ and saturation vapor pressure $e_{s}$, we estimated the saturation vapor pressure using the modified Tetens formula used in the IFS model (Simmons et al. 1999; ECMWF 2007). The saturation vapor pressure is that over ice for temperatures below $-23^{\circ} \mathrm{C}$, that over liquid water for temperatures above $0^{\circ} \mathrm{C}$, and a quadratic interpolation between the saturation vapor pressures over ice and liquid water for intermediate, "mixed-phase" temperatures.

\section{Results}

\section{a. Zonal-mean relative humidity}

For a direct comparison with the zonally and temporally averaged water vapor balance inferred from ERA-40 data by Schneider et al. (2006), we first present results for zonal and temporal means for DJF inferred from the IFS data. That is, we first take the mean $\overline{(\cdot)}^{*}$ to be a temporal and zonal mean and fluctuations $(\cdot)^{\prime}$ to be fluctuations about this mean, so that eddy terms include contributions from stationary eddies.

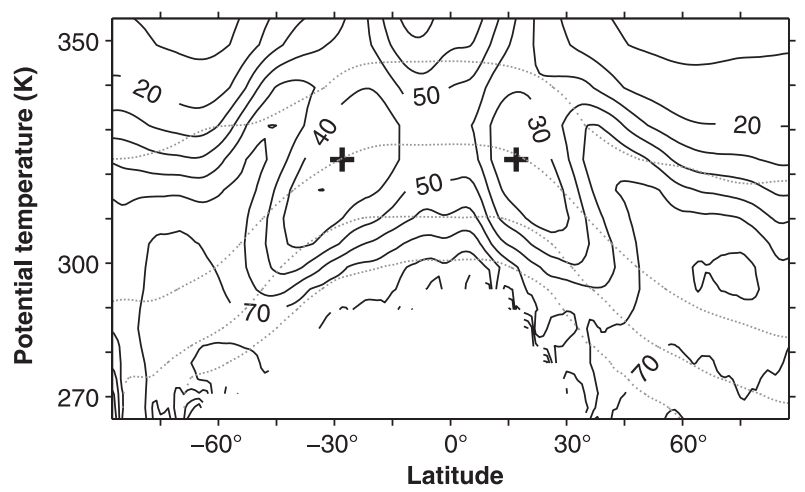

FIG. 1. Zonally and seasonally averaged relative humidity $\bar{H}^{*}$ (\%) for DJF 1998/99. The crosses mark the relative humidity minima in the subtropical free troposphere. The dotted lines are the 250-, 500-, 750-, and 925-hPa pressure contours. Near the lower boundary, relative humidity contours at any given latitude are truncated at the lowest potential temperature that occurred at that latitude in DJF 1998/99.

Figure 1 shows the zonally and seasonally averaged relative humidity $\bar{H}^{*}$, along with a few contours of the zonally and seasonally averaged pressure $\bar{p}$ on isentropes to facilitate the positioning of isentropic levels in the atmosphere. The crosses mark the minima of the zonal-mean relative humidity in the subtropical free troposphere. They are located between about $20^{\circ}$ and $30^{\circ}$ latitude at a potential temperature of $\sim 323 \mathrm{~K}$, which corresponds to a mean pressure of $\sim 500 \mathrm{hPa}$ or a mean altitude of $\sim 5.5 \mathrm{~km}$. As noted in previous studies (e.g., Peixoto and Oort 1996; Schneider et al. 2006), the relative humidity minimum is more pronounced in the winter hemisphere, in the descending branch of the strong crossequatorial Hadley cell.

\section{b. Zonal-mean water vapor balance}

Figure 2 shows the dominant terms in the zonally and seasonally averaged water vapor balance (5). It reveals that the water vapor balance inferred from the IFS data is qualitatively consistent with that inferred from ERA-40 data, although here we use only daily data for one season, as opposed to the 4-times-daily data for 21 seasons used in the earlier study.

- Isentropic meridional eddy fluxes of water vapor diverge near the surface and in the tropical free troposphere and converge in the extratropical free troposphere. The divergence of the isentropic meridional eddy fluxes changes sign near the subtropical relative humidity minima, from positive equatorward to negative poleward; therefore, it is generally small in the vicinity of the minima (Fig. 2a). That is, isentropic eddy fluxes transport water vapor meridionally from the deep tropics through the subtropics into the extratropics, 

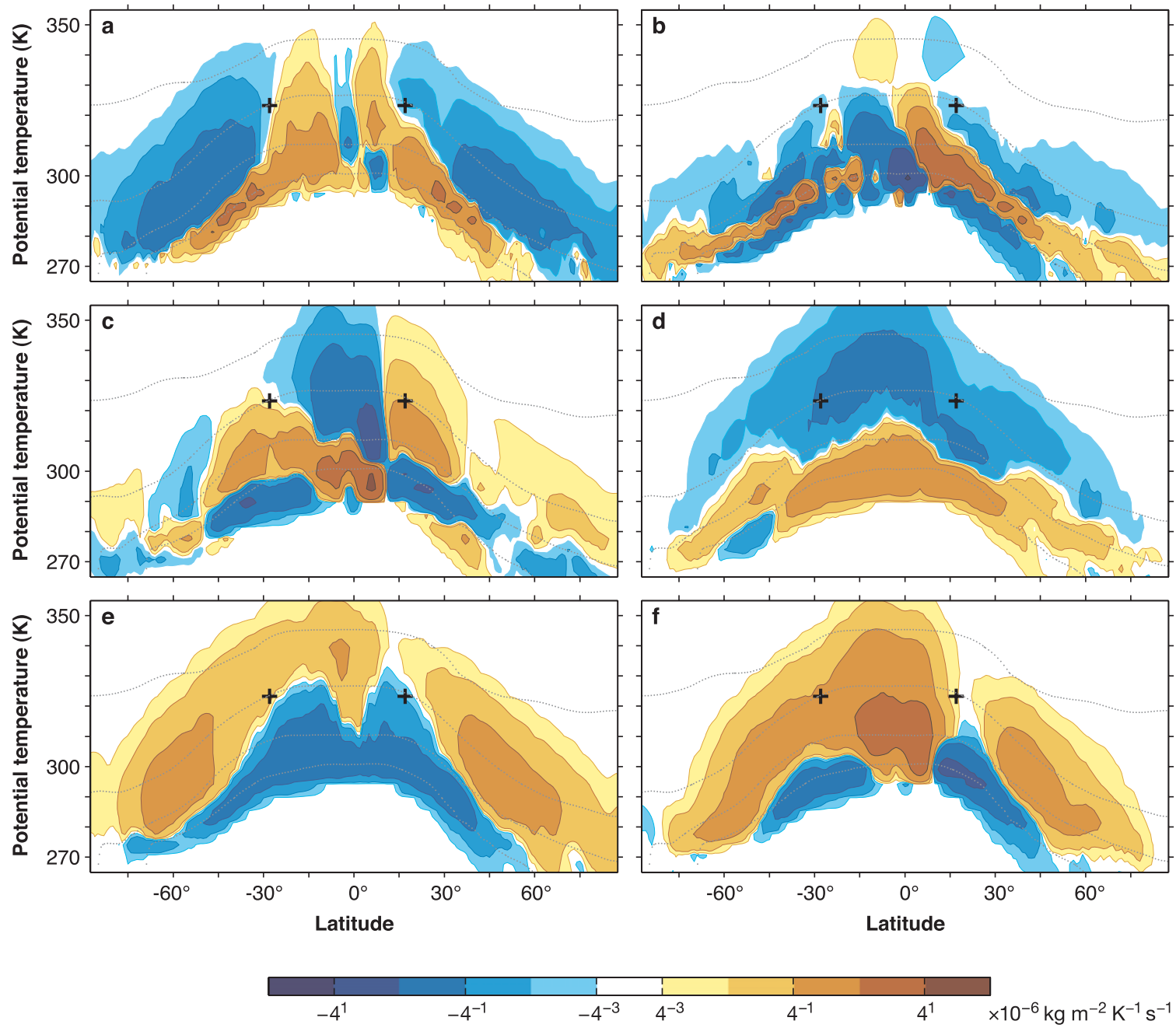

FIG. 2. Zonally and seasonally averaged water vapor balance for DJF 1998/99: (a) divergence $\nabla_{\theta} \cdot\left(\bar{\rho}_{\theta}{\overline{\mathbf{v}^{\prime}} q^{\prime}}^{*}\right)$ of isentropic eddy fluxes; (b) divergence $\nabla_{\theta} \cdot\left(\bar{\rho}_{\theta} \overline{\mathbf{v}}^{*} \bar{q}^{*}\right)$ of isentropic mean fluxes; (c) divergence $\partial_{\theta}\left(\bar{\rho}_{\theta} \bar{Q}^{*} \bar{q}^{*}\right)$ of cross-isentropic mean fluxes; (d) divergence $\partial_{\theta}\left(\bar{\rho}_{\theta} \overline{Q^{\prime} q^{\prime}}{ }^{*}\right)$ of cross-isentropic eddy fluxes; (e) grid-scale water vapor sink $-\bar{\rho}_{\theta} \bar{S}_{g}^{*}$; (f) subgrid-scale water vapor sink $-\bar{\rho}_{\theta}\left(\bar{S}_{c}^{*}+\bar{S}_{t}^{*}\right)$. The contouring is logarithmic, with contour levels separated by factors of 4 . As in Fig. 1, the crosses mark the relative humidity minima in the subtropical free troposphere, and the dotted lines are the 250-, 500-, 750-, and 925-hPa pressure contours.

but they do not exert a substantial net drying or moistening near the subtropical relative humidity minima. This finding contrasts with the suggestion of Galewsky et al. (2005) that meridional eddy transport of water vapor primarily controls the dryness of the subtropical free troposphere, a suggestion based on the finding that most air near the subtropical relative humidity minima was last saturated along isentropic paths extending into the extratropical free troposphere. However, the findings of Galewsky et al. (2005) and ours are not necessarily inconsistent with each other, as Galewsky et al. focused on the isentropic poleward transport of water vapor out of the subtropics into the extratropics; the isentropic poleward transport of water vapor out of the deep tropics into the subtropics is of similar magnitude, leading to no substantial net drying or moistening near the subtropical relative humidity minima; see Schneider et al. (2006) for further discussion.

- Isentropic mean meridional fluxes of water vapor, associated with the mean meridional mass circulation in isentropic coordinates, play a significant role in the water vapor balance near the surface; however, their divergence or convergence near the subtropical relative humidity minima is likewise small, though they do have a consistent sign (convergence) in the vicinity of the minima and contribute to moistening there (Fig. 2b).

- Cross-isentropic mean fluxes of water vapor in the free troposphere represent the dominant drying process near the subtropical relative humidity minimum in the 
Northern Hemisphere, in the descending branch of the strong cross-equatorial Hadley cell (Fig. 2c). That large-scale subsidence is an important drying process in the subtropical free troposphere is in agreement with previous observational and modeling studies (e.g., Sherwood 1996a,b; Salathé and Hartman 1997; Sherwood and Meyer 2006; Ryoo et al. 2009). However, the cross-isentropic mean fluxes of water vapor near the subtropical relative humidity minimum in the Southern Hemisphere are weak, as the summer Hadley cell is weak. Because the convergence of isentropic meridional (mean and eddy) fluxes of water vapor near the Northern Hemisphere relative humidity minimum is smaller in magnitude than the divergence of the cross-isentropic mean fluxes, the drying by crossisentropic mean subsidence must be partially balanced by cross-isentropic upward advection of water vapor or the water vapor source (e.g., evaporation/sublimation of condensate that may have arrived near the minimum by advection and sedimentation).

These findings confirm those of Schneider et al. (2006, their Fig. 8), albeit with some quantitative differences. For example, the divergences of the cross-isentropic mean flux of water vapor differ near the surface and near the Southern Hemisphere relative humidity minimum, where there was more pronounced divergence in the ERA-40 data in the long-term mean than there is in the IFS data for the one season we analyzed. (The differences between the analyses are not solely caused by interannual variability but indicate genuine differences between the datasets; we have verified this by computing the quantities shown here from the ERA-40 data only for DJF 1998/99. In general, the conclusions of the earlier study are unchanged if only one season rather than a multidecadal average is considered, suggesting that the shortness of the record we analyze here likewise does not represent a serious limitation.)

Unlike in Schneider et al. (2006), here we can determine individual components of the water vapor source $\bar{\rho}_{\theta} \bar{S}^{*}$ and of the divergence of the cross-isentropic eddy fluxes $\partial_{\theta}\left(\bar{\rho}_{\theta} \overline{Q^{\prime} q^{\prime}} *\right.$ ) on the right-hand side of the mean water vapor balance (5). Thus, we can disentangle different drying and moistening processes near the subtropical relative humidity minima. Near the Northern Hemisphere relative humidity minimum, the dominant moistening process balancing the drying by cross-isentropic mean subsidence is convergence of cross-isentropic eddy fluxes of water vapor (Fig. 2d). The cross-isentropic eddy fluxes generally diverge near the surface and converge in the free troposphere, implying water vapor transport from the surface upward. Grid-scale evaporation/sublimation of condensate contributes to the moistening of the sub-

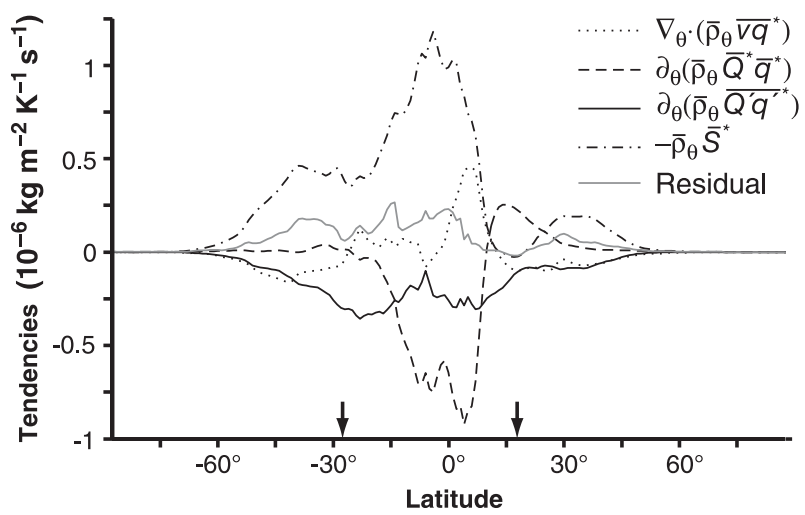

FIG. 3. Zonally and seasonally averaged water vapor balance for DJF $1998 / 99$ on the $323-K$ isentrope. Shown are drying tendencies owing to the terms indicated, corresponding to sections through Fig. 2 along the $323-\mathrm{K}$ isentrope. The divergence of isentropic fluxes $\nabla_{\theta} \cdot\left(\bar{\rho}_{\theta} \overline{\mathbf{v}}^{*}\right)$ corresponds to the sum of Figs. 2a,b; the divergence $\partial_{\theta}\left(\bar{\rho}_{\theta} \bar{Q}^{*} \bar{q}^{*}\right)$ of cross-isentropic mean fluxes corresponds to Fig. 2c; the divergence $\partial_{\theta}\left(\bar{\rho}_{\theta} \bar{Q}^{\prime} q^{\prime} *\right)$ of cross-isentropic eddy fluxes corresponds to Fig. $2 \mathrm{~d}$; and the water vapor sink $-\bar{\rho}_{\theta} \bar{S}^{*}$ corresponds to the sum of Figs. 2e and $\mathrm{f}$. The residual is the lefthand side of the water vapor balance (5) minus the right-hand side. The arrows mark the latitudes of the relative humidity minima in the subtropical free troposphere.

tropical free troposphere, but primarily below the relative humidity minima (Fig. 2e). Near the Southern Hemisphere relative humidity minimum, the dominant drying process is subgrid-scale condensation in convection (Fig. 2f); this approximately balances the moistening by convergence of cross-isentropic eddy fluxes of water vapor (Fig. 2d). Because the cross-isentropic eddy fluxes and the subgrid-scale condensation may both be associated with moist convection (as discussed further in section $4 \mathrm{e}$ ), the two dominant terms near the Southern Hemisphere relative humidity minimum may represent different aspects of the same physical process.

The residual of the zonally and seasonally averaged water vapor balance (5) is about an order of magnitude smaller than the dominant terms near the relative humidity minima, but it is not small compared with the higher-order terms. This is illustrated in Fig. 3, which shows the residual and terms in Fig. 2 along the 323-K isentrope. The $323-\mathrm{K}$ isentrope lies in the midtroposphere in the tropics and subtropics and reaches the tropopause in higher latitudes (Fig. 1). It crosses the subtropical relative humidity minima. The smallness of the residual relative to the dominant terms is evident (Fig. 3) and, at least within the IFS framework and its limitations, confirms the robustness of our inferences.

The results so far indicate that cross-isentropic eddy fluxes of water vapor play a dominant role in the water vapor balance of the free troposphere and, in particular, that they are essential for moistening the subtropical 


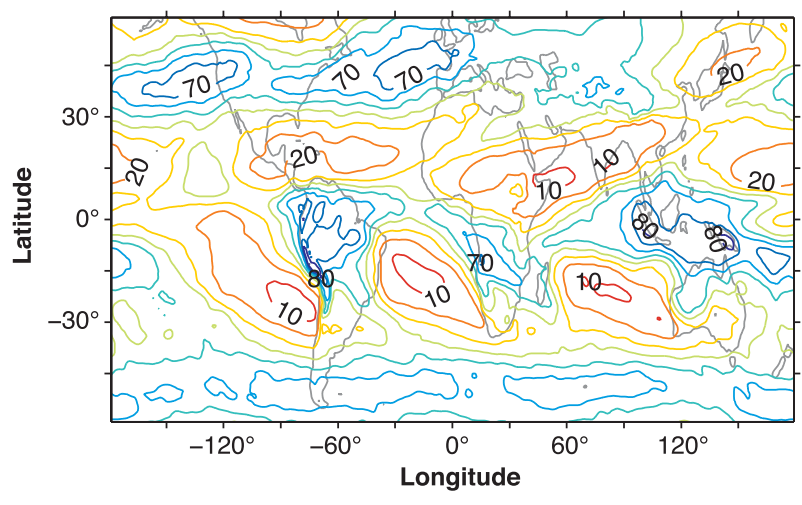

FIG. 4. Relative humidity $\bar{H}^{*}$ (\%) for DJF $1998 / 99$ on the $323-\mathrm{K}$ isentrope. Contour interval is $10 \%$.

free troposphere, as suggested in Schneider et al. (2006). Regional information and a further decomposition of the diabatic and water vapor source terms provide insight into the physical processes involved.

\section{c. Water vapor flux along and across the $323-K$ isentrope}

We analyze the regional water vapor balance as a function of latitude and longitude on the $323-\mathrm{K}$ isentrope. Here and henceforth, we take the mean $\overline{(\cdot)^{*}}$ to be only a temporal mean, and fluctuations $(\cdot)^{\prime}$ to be fluctuations about this mean, so that eddy terms include contributions only from transient eddies (understood to encompass variability on all subseasonal time scales).

Figure 4 shows the seasonally averaged relative humidity on the $323-\mathrm{K}$ isentrope. It is evident that the zonally averaged relative humidity (Fig. 1) masks rich regional structure (Fig. 4). The driest regions are found over oceans in the Southern (summer) Hemisphere subtropics, with relative humidities of $\sim 10 \%$, for example, over portions of the eastern Pacific, Atlantic, and Indian Oceans; the regions over the adjacent continents are relatively moist, with relative humidities above $60 \%$. In the Northern (winter) Hemisphere subtropics, the relative humidity has a less pronounced regional structure, with large regions with relative humidities of $\sim 20 \%$. While the winter subtropics are drier than the summer subtropics in the zonal mean (Fig. 1), the zonal-mean relative humidity in the summer subtropics is an average of extremely dry oceanic regions and much moister continental regions. See Dessler and Minschwaner (2007) for a similar analysis based on satellite data.

Figure 5 shows components of the divergence of the water vapor fluxes along and across the $323-\mathrm{K}$ isentrope. They exhibit a similarly rich regional structure as the relative humidity. While the divergence of the zonally and temporally averaged isentropic (mean and eddy) fluxes of water vapor near the subtropical relative hu- midity minima is relatively small (Figs. 2a,b), there is, at the same latitudes, substantial regional convergence of the temporally averaged isentropic fluxes in drier regions and divergence in moister regions (Figs. 5a,b). For example, in the Southern Hemisphere subtropics, there is convergence of isentropic mean and eddy fluxes in the driest oceanic regions and divergence in moister regions. In the Northern Hemisphere subtropics (near $\sim 20^{\circ} \mathrm{N}$ ), there is convergence in dry regions over the Atlantic and Pacific and divergence in other regions, though here the zonal asymmetries are less pronounced, as for the relative humidities (cf. Fig. 4). Therefore, although meridional transport of water vapor by isentropic fluxes is not consistently important in moistening subtropical dry regions in the zonal mean, isentropic fluxes redistribute water vapor zonally and are important regionally in the subtropics. Mean zonal circulations (including Walker circulations and circulations associated with stationary eddies) are more important in this redistribution of water vapor than transient eddy fluxes, as can be seen by the larger magnitude of the fluxes in Fig. 5b than in Fig. 5a. The mean circulations must have a relatively shallow component given that the $323-\mathrm{K}$ isentrope lies in the midtroposphere. Particularly the isentropic eddy fluxes of water vapor exhibit southwest-northeast streaks in the Northern Hemisphere and northwest-southeast streaks in the Southern Hemisphere (Fig. 5a). These streaks are manifestations of the well-known fact that much of the poleward water vapor transport is carried in "atmospheric rivers"- filamentary intrusions of extratropical cyclones into low latitudes, which transport water vapor from moist low-latitude regions toward the extratropical storm tracks along paths that slant eastward away from the equator (e.g., Newell et al. 1992; Zhu and Newell 1998; Waugh 2005).

The divergences of cross-isentropic water vapor fluxes on the $323-\mathrm{K}$ isentrope exhibit greater spatial coherence than the divergences of the isentropic fluxes. The crossisentropic eddy flux of water vapor converges almost everywhere, primary exceptions being some regions over tropical and subtropical land surfaces (Fig. 5c). In the Southern Hemisphere subtropics, the convergence is weakest in the driest regions, consistent with suppression of turbulence and convection there, and the regions of divergence generally coincide with the moister regions (cf. Fig. 4). In the Northern Hemisphere subtropics, a correlation between weaker convergence and lower relative humidity can also be seen, though, like the relative humidity, the convergence has less pronounced spatial structure than in the Southern Hemisphere subtropics.

The cross-isentropic mean flux of water vapor converges in ascending and diverges in descending branches of overturning circulations. That is, it converges in the 

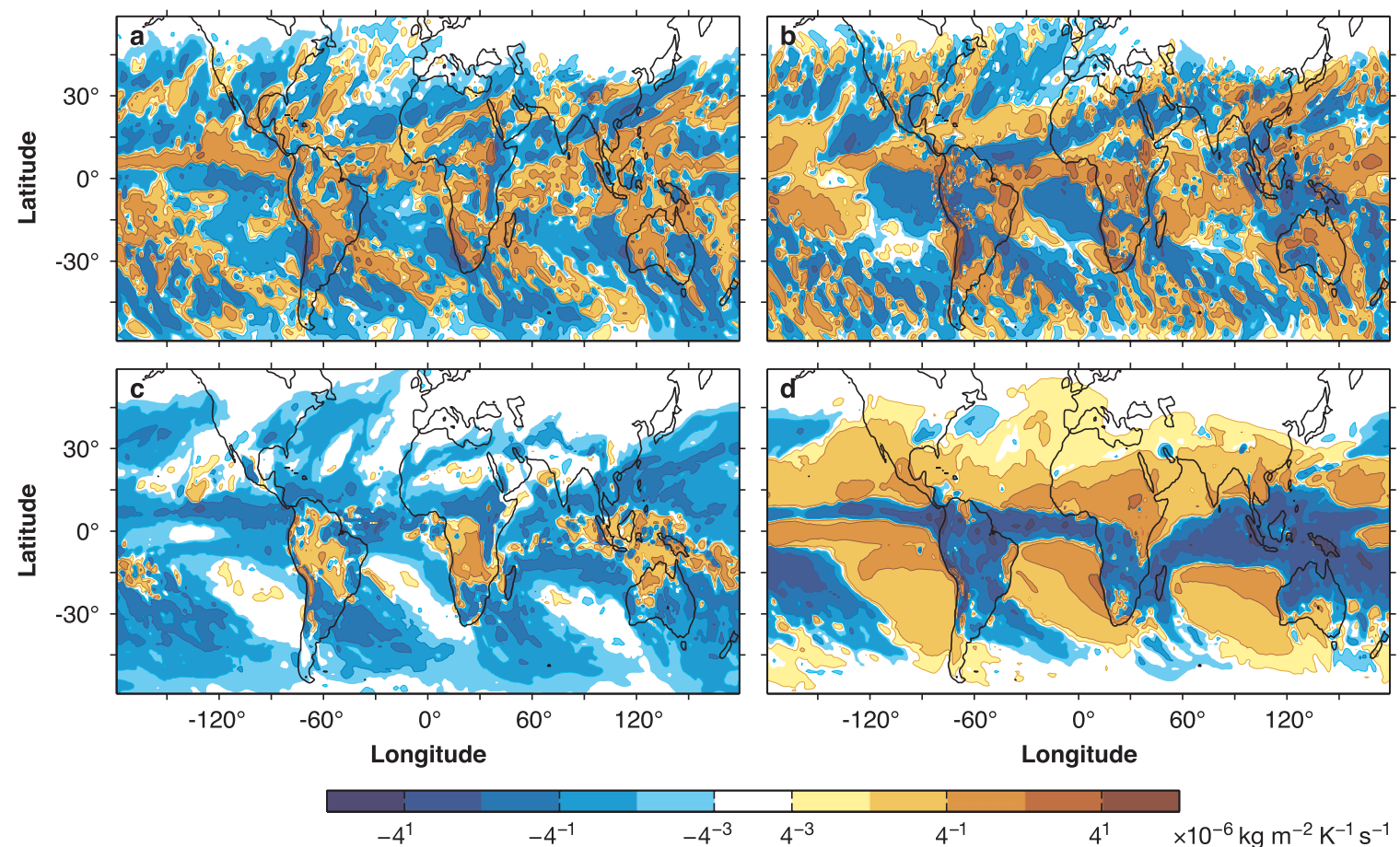

FIG. 5. Divergence of water vapor flux for DJF $1998 / 99$ on the $323-\mathrm{K}$ isentrope: (a) isentropic eddy component $\nabla_{\theta} \cdot\left(\bar{\rho}_{\theta} \overline{\mathbf{v}^{\prime} q^{\prime}} *\right)$; (b) isentropic mean component $\nabla_{\theta} \cdot\left(\bar{\rho}_{\theta} \overline{\mathbf{v}}^{*} \bar{q}^{*}\right)$; (c) cross-isentropic eddy component $\partial_{\theta}\left(\bar{\rho}_{\theta}{\overline{Q^{\prime} q^{\prime}}}^{*}\right)$; (d) cross-isentropic mean component $\partial_{\theta}\left(\bar{\rho}_{\theta} \bar{Q}^{*} \bar{q}^{*}\right)$.

ITCZ and in other convergence zones, primarily over subtropical continents in the summer hemisphere and over the western Pacific; it diverges elsewhere in the subtropics (Fig. 5d). It is evident that also regionally, crossisentropic mean subsidence dries the subtropical free troposphere more strongly than do isentropic water vapor fluxes. The driest regions in the subtropics coincide with strong cross-isentropic mean subsidence (cf. Fig. 4). The isentropic eddy flux of water vapor generally opposes the drying or moistening by cross-isentropic mean subsidence or ascent in the subtropics (compare Fig. 5a with 5d).

We can further decompose the divergences of the cross-isentropic mean and eddy fluxes of water vapor into components associated with dynamic processes $\left(Q_{d}=Q_{c}+Q_{L}+Q_{t}\right)$ and radiative processes $\left(Q_{R}\right)$, as in Fig. 6. (We understand dynamic processes to include parameterized dynamic processes such as convection and subgrid-scale turbulence, which are sometimes referred to as "model physics" and treated as distinct from the grid-scale model dynamics.) The diabatic heating $Q_{d}$ associated with dynamic processes is the net diabatic heating of processes such as convective heating and cooling owing to grid-scale evaporation/sublimation of condensate in convective downdrafts. These processes are spatially correlated and physically related, yet appear in different subgrid-scale parameterization terms
$\left(Q_{c}\right.$ and $\left.Q_{L}\right)$ in the IFS model. Here we consider them together.

Like the total cross-isentropic eddy flux of water vapor (Fig. 5c), the cross-isentropic dynamic eddy flux converges over most oceanic regions in the subtropics, except in the driest regions of the summer subtropics, where it is close to zero; it diverges in strongly convective regions, particularly over continents in the summer hemisphere (Fig. 6a). The cross-isentropic dynamic mean flux converges throughout most of the atmospheremore strongly in the ITCZ and in other convergence zones (e.g., over subtropical continents in the summer hemisphere) than in the driest regions over oceans (Fig. 6b). It is primarily the net of fluxes associated with convective heating and with cooling owing to grid-scale evaporation/sublimation of condensate. The flux associated with subgrid-scale turbulence $\left(Q_{t}\right)$, included in Fig. 6 b, plays a subordinate role, being significant primarily over subtropical continents in the summer hemisphere. As was to be expected given the long radiative time scales, the divergence or convergence of the crossisentropic radiative eddy flux generally is smaller than that of the cross-isentropic dynamic eddy flux (Fig. 6c), so that the divergence or convergence of the total crossisentropic eddy flux (Fig. 5c) is dominated by the dynamic eddy component (Fig. 6a). The cross-isentropic 

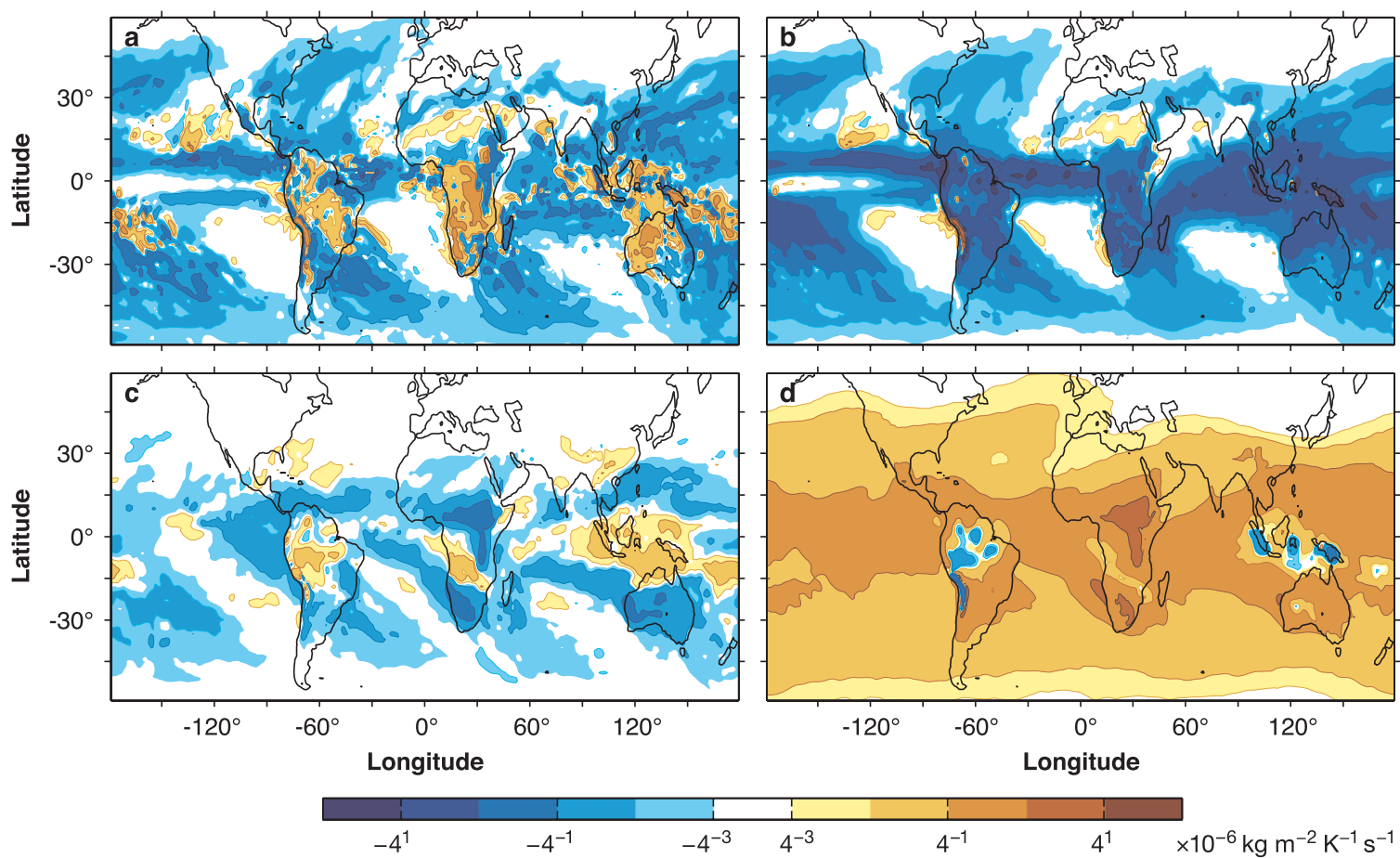

FIG. 6. Divergence of cross-isentropic flux of water vapor for DJF 1998/99 on the 323-K isentrope: (a) dynamic eddy component $\partial_{\theta}\left(\bar{\rho}_{\theta} \overline{Q_{d}^{\prime} q^{\prime}} *\right.$; $)$ (b) dynamic mean component $\partial_{\theta}\left(\bar{\rho}_{\theta} \bar{Q}_{d}^{*} \bar{q}^{*}\right) ;$ (c) radiative eddy component $\partial_{\theta}\left(\bar{\rho}_{\theta}{\overline{Q_{R}}}^{\prime}{ }^{*}\right.$ ); (d) radiative mean component $\partial_{\theta}\left(\bar{\rho}_{\theta} \bar{Q}_{R} * \bar{q}^{*}\right)$.

radiative mean flux diverges throughout most of the atmosphere, as is expected from the predominance of radiative cooling and associated cross-isentropic mean subsidence in the free troposphere (Fig. 6d).

The decomposition of the cross-isentropic mean flux of water vapor reveals that locally cross-isentropic mean subsidence driven by radiative cooling and the associated drying are partially offset or overcompensated by crossisentropic mean ascent owing to convective heating and the associated moistening, for example, over subtropical continents in the summer hemisphere and over subtropical oceans in the winter hemisphere (compare Figs. $6 \mathrm{~b}$ and $6 \mathrm{~d}$ ). Without this mean ascent, the divergence of the net cross-isentropic mean flux of water vapor in the subtropics would be more pronounced (Fig. 5d). The drying by cross-isentropic mean subsidence would dominate the water vapor balance near the subtropical relative humidity minimum not only in the Northern Hemisphere but also in the Southern Hemisphere (cf. Fig. 2c), and the subtropical free troposphere would be considerably drier than it already is, particularly in the summer hemisphere. The decomposition of the cross-isentropic mean flux in Fig. 6 also makes clear that, as is well known, even in frequently convective regions such as the ITCZ, subsidence driven by radiative cooling occurs a substantial fraction of the time (Riehl and Malkus 1958).

\section{d. Water vapor sink on the 323-K isentrope}

Figure 7 shows components of the water vapor sink $-\bar{\rho}_{\theta} \bar{S}^{*}$. In low latitudes, convective processes generally dominate the water vapor sink (compare Figs. 7a and 7b). There is strong drying by condensation in convection in the ITCZ and in other convergence zones (Fig. 7b); it is locally partially offset by moistening by grid-scale evaporation/sublimation of condensate (Fig. 7c), which includes evaporation/sublimation of condensate in convective clouds. However, moistening by grid-scale evaporation/sublimation of condensate in low latitudes is generally weaker than moistening by convergence of cross-isentropic fluxes of water vapor (compare Figs. 6a and $6 \mathrm{~b}$ with Fig. $7 \mathrm{c}$ ). In higher latitudes, drying by gridscale condensation dominates the water vapor sink (Fig. $7 \mathrm{c})$. The water vapor sink associated with subgrid-scale turbulence is generally small at the level in the free troposphere we consider, except near the tops of major mountains (Fig. 7d).

\section{e. Synthesis}

The distinction between contributions to the subgridscale water vapor sink $-\bar{\rho}_{\theta} \bar{S}^{*}$ and contributions to the divergence of the cross-isentropic flux $\partial_{\theta}\left(\bar{\rho}_{\theta} \overline{Q q}^{*}\right)$ is to some degree artificial, dictated by the structure of 

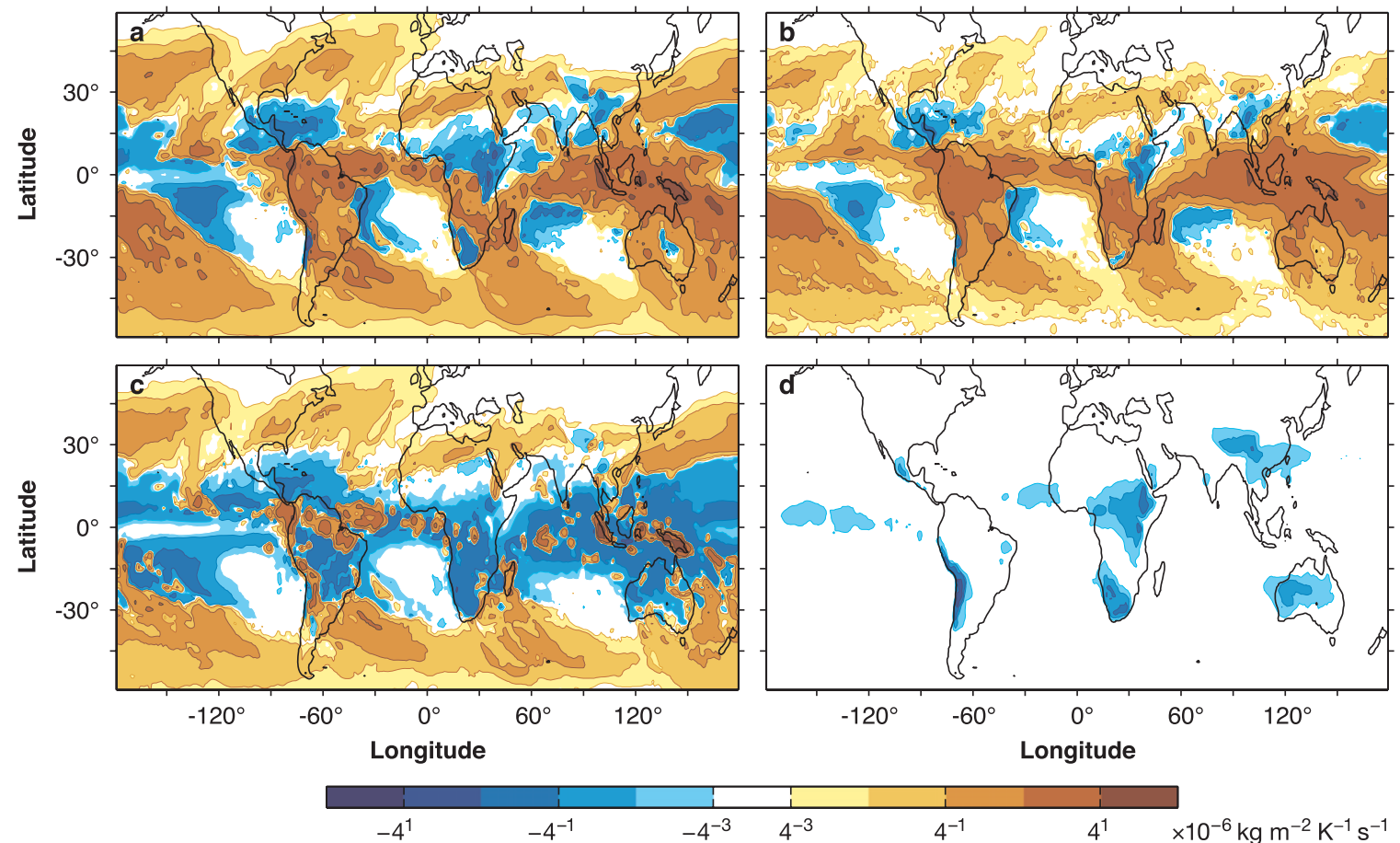

FIG. 7. Water vapor sink for DJF $1998 / 99$ on the $323-\mathrm{K}$ isentrope: (a) total water vapor sink $-\bar{\rho}_{\theta} \bar{S}^{*}$; (b) component $-\bar{\rho}_{\theta} \bar{S}_{c}^{*}$ associated with convection; (c) component $-\bar{\rho}_{\theta} \bar{S}_{g}^{*}$ associated with grid-scale condensation and evaporation/sublimation; (d) component $-\bar{\rho}_{\theta} \bar{S}_{t}^{*}$ associated with subgrid-scale turbulence.

parameterizations in the IFS model rather than by distinctions among physical processes. For example, the subgrid-scale convective water vapor sink (Fig. 7b), which represents the net of condensation and evaporation/ sublimation of condensate in convective clouds, is a result of the same convective processes that give rise to the divergence of convective cross-isentropic water vapor fluxes (contributing to Figs. 6a and 6b). Likewise, the gridscale evaporation/sublimation of condensate appearing in the grid-scale water vapor sink (Fig. 7c) includes a component that represents evaporation/sublimation of condensate in convective clouds, in addition to evaporation/ sublimation in stratiform clouds.

Figure 8 therefore combines the various cross-isentropic flux and water vapor sink terms, distinguishing only radiative and dynamic components. It is clear that radiative processes generally cool the free troposphere and hence lead to subsidence and a drying tendency (Fig. 8a). This is the dominant drying process in the subtropical free troposphere. The radiative drying in the subtropical free troposphere is locally partially offset or overcompensated by dynamic moistening associated with cross-isentropic fluxes and water vapor sources, including convection and evaporation/sublimation of condensate (Fig. 8b); as we have seen, moistening by evaporation/sublimation of condensate (Fig. 7) plays a subordinate role to moistening by convergence of cross-isentropic water vapor fluxes (Figs. 6a,b). The dynamic moistening associated with cross-isentropic fluxes and water vapor sources dominates over the radiative drying along the ITCZ and in some subtropical regions, such as over subtropical continents and over the central Pacific in the Southern Hemisphere and over the western Atlantic and western Pacific in the Northern Hemisphere. In the driest regions of the summer hemisphere subtropics, the dynamic moistening is suppressed (Fig. 8b). Near the subtropical relative humidity minima, the radiative drying and the dynamic moistening associated with cross-isentropic fluxes and water vapor sources balance approximately in the zonal mean (Figs. 2 and 3); however, locally they do not balance everywhere in the subtropics (Fig. 8).

The picture that emerges is that cross-isentropic subsidence of dry air, driven by radiative cooling, is the dominant drying process in the subtropical free troposphere. In some subtropical regions (e.g., over continents in the summer hemisphere and over western portions of ocean basins in the winter hemisphere), this radiative drying is partially offset or overcompensated by crossisentropic dynamic transport of water vapor from the surface upward. This dynamic transport is associated with processes such as continental convection (in the summer hemisphere) and frontal convection in filamentary 

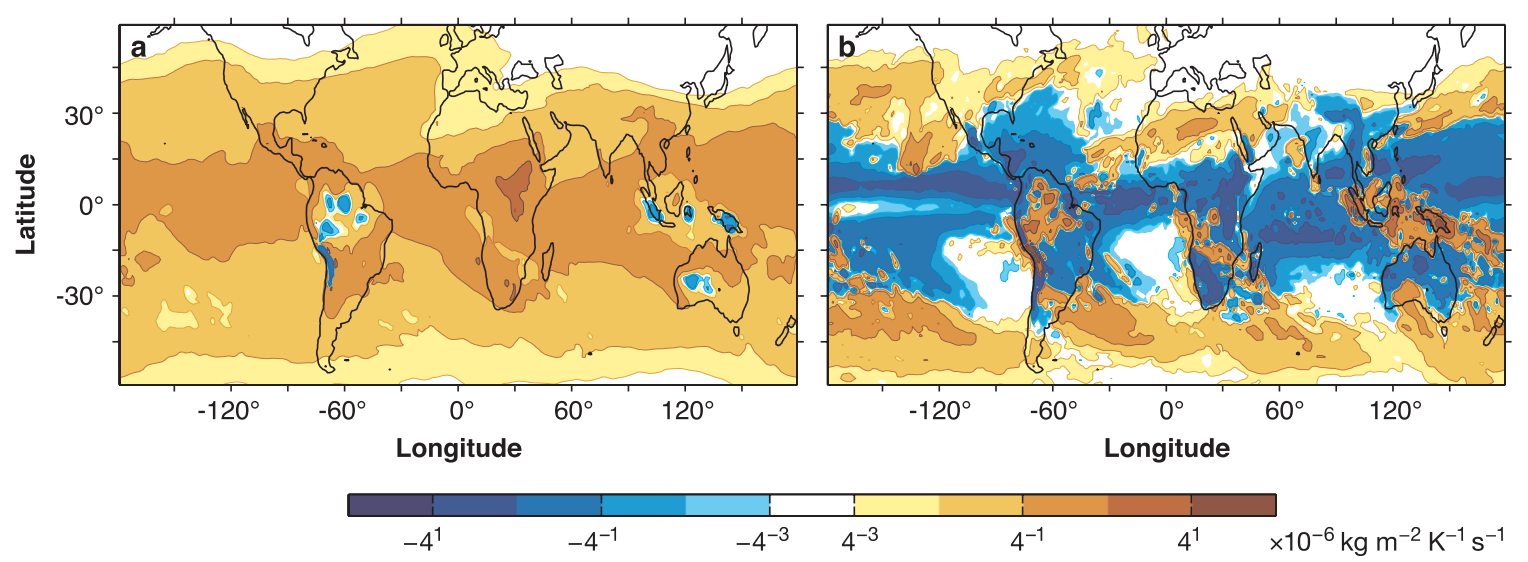

FIG. 8. Drying tendencies owing to cross-isentropic fluxes and water vapor sinks for DJF 1998/99 on the 323-K isentrope: (a) tendency $\partial_{\theta}\left(\bar{\rho}_{\theta} \bar{Q}_{R} q *\right)$ associated with radiative processes; (b) tendency $\partial_{\theta}\left(\bar{\rho}_{\theta} \bar{Q}_{d} q{ }^{*}\right)-\bar{\rho}_{\theta} \bar{S}^{*}$ associated with dynamic processes.

intrusions of extratropical cyclones into low latitudes (e.g., Newell et al. 1992; Zhu and Newell 1998; Waugh 2005). The degree to which dynamic moistening by cross-isentropic water vapor transport compensates radiative drying controls the regional relative dryness of the subtropical free troposphere. Any resultant net drying or moistening of the subtropical free troposphere is regionally balanced by isentropic transport of water vapor from moister into drier regions, which moderates relative humidity contrasts; mean circulations and stationary eddies are more important in this (primarily zonal) transport than transient eddies. Evaporation/ sublimation of cloud condensate also contributes to the moistening of the subtropical free troposphere but generally is less important than dynamic water vapor transport, consistent with other observational and modeling studies (e.g., Sherwood 1996b; Pierrehumbert and Roca 1998; Luo and Rossow 2004; Galewsky et al. 2005; Dessler and Minschwaner 2007; Wright et al. 2009).

\section{f. Residual and uncertainties}

To check the consistency of our inferences, we calculated the residual of the seasonally averaged water vapor balance (5). The residual in the free troposphere is generally smaller than the dominant terms we discussed, often by about an order of magnitude, but not everywhere. In the Northern Hemisphere subtropics, the residual is spatially noisy and does not exhibit distinguished large-scale structure. In the Southern Hemisphere subtropics, the residual does exhibit some large-scale spatial structure, for example, near the very dry oceanic regions, where it points to a systematic lack of closure of the water vapor balance (5): the right-hand side exceeds the left-hand side by up to $\sim 0.5 \times 10^{-6} \mathrm{~kg} \mathrm{~m}^{-2} \mathrm{~K}^{-1} \mathrm{~s}^{-1}$. There is also a systematic lack of closure of similar magnitude in and near the ITCZ. Some of this lack of closure may arise because of the data assimilation process, errors within it, and interpolation errors; some of it may arise because in the calculation of cross-isentropic fluxes $\overline{Q q}^{*}$, we used 24-h integrated mean fields for diabatic heating rates $Q$ but means of 12- and 24-h instantaneous fields for specific humidities $q$, resulting in aliasing errors. Nonetheless, the residual is small enough and exhibits sufficiently little spatial structure in the subtropics that our inferences about the dominant terms in the water vapor balance of the subtropical free troposphere appear qualitatively consistent within the IFS framework; however, individual terms may have substantial quantitative errors.

The IFS framework likely has limitations that may affect our analysis. For example, it is known that the cross-equatorial DJF Hadley cell in the ERA-40 data is stronger than it is in other datasets (Mitas and Clement 2005), and this may affect the strength of the divergence of cross-isentropic mean water vapor fluxes in the descending branch of the Hadley cell. The divergence of cross-isentropic mean water vapor fluxes in the descending branch of the Hadley cell in the IFS data is approximately equal to that in the ERA-40 data, so the two datasets may have similar deficiencies. However, the strength of the Hadley cell in the ERA-40 data differs by at most $25 \%$ from that in other datasets, and the differences are smaller among the most recent datasets (Mitas and Clement 2005). These discrepancies among the datasets are too small to affect our inferences qualitatively. Similarly, as stated in Schneider et al. (2006), the isentropic eddy fluxes of water vapor are based on large-scale flow fields and, to be substantially in error, would require large biases in the correlation between specific humidities and horizontal velocities. Biases of sufficient magnitude to render our inferences qualitatively invalid appear unlikely. 
A major limitation of our analysis is that it is based on data for just one season, as only a very limited dataset was available to us. We have verified that the analysis in Schneider et al. (2006) for the zonal mean leads to unchanged conclusions if it is restricted to the same one season on which we focused here, giving us confidence that the inferences for the zonal mean are robust and are not marred by interannual variability. By subsampling the IFS data for DJF 1998/99 to the center half of the DJF season (24 December 1998 to 6 February 1999), we have also verified the robustness of our conclusions for the zonal variations in the water vapor balance. The spatial structure and magnitude of the terms shown in Figs. 1-8 remain unchanged if the analysis is restricted to half the IFS data. For example, the streaks in the divergence of isentropic eddy fluxes of water vapor in Fig. 5a are still present if the same figure is produced using the subsampled data, giving us confidence in interpreting them as "atmospheric rivers."

\section{Conclusions}

To elucidate how the relative humidity of the subtropical free troposphere is maintained, we have examined the relative importance of different processes in the water vapor balance in isentropic coordinates using high-resolution hindcast data from the ECMWF Integrated Forecast System for DJF 1998/99. The analysis identified dominant terms in the water vapor balance, which can be partially associated with distinct physical processes; however, it cannot make quantitative statements about the relative humidity that would be realized if one or another of the processes identified were absent or quantitatively changed when the climate changes.

In the zonal mean, isentropic mean and eddy fluxes transport water vapor meridionally from the deep tropics through the subtropics into the extratropics. However, their convergence and the associated moistening in the vicinity of the relative humidity minima is generally weaker than the dominant drying processes, in agreement with the findings of Schneider et al. (2006). Near the Northern (winter) Hemisphere relative humidity minimum, the dominant drying process is cross-isentropic mean subsidence in the descending branch of the strong cross-equatorial Hadley cell. The dominant moistening process balancing this drying is convergence of the crossisentropic eddy flux of water vapor, transporting water vapor from the surface upward. Moistening by convergence of isentropic mean and eddy fluxes of water vapor also contributes, and grid-scale evaporation/sublimation of condensate provides a secondary moisture source at lower levels. Near the Southern (summer) Hemisphere relative humidity minimum, the dominant moistening process is also divergence of the cross-isentropic eddy flux of water vapor. But the dominant drying process, in the zonal mean, is condensation in moist convection and not mean subsidence as in the winter hemisphere. This indicates a primarily convectively controlled zonal-mean relative humidity in the summer hemisphere (since the cross-isentropic eddy flux of water vapor is also primarily convective).

The regional analysis of the water vapor balance presented here reveals the importance of zonal inhomogeneities. Cross-isentropic subsidence of dry air, driven by radiative cooling, is the dominant drying process in the subtropical free troposphere, not only in the winter hemisphere but also in the summer hemisphere. In some subtropical regions (e.g., over continents in the summer hemisphere), the drying by radiative subsidence is partially offset or overcompensated by cross-isentropic dynamic transport of water vapor from the surface upward (e.g., in convection). Near the summer hemisphere relative humidity minimum, drying by mean radiative subsidence and moistening by convergence of mean cross-isentropic water vapor transport balance approximately in the zonal mean, but not regionally. The regional imbalance between drying by radiative subsidence and moistening by cross-isentropic dynamic transport of water vapor controls the regional relative dryness of the subtropical free troposphere and leads, for example, to the extreme dryness of oceanic regions in the summer hemisphere. Any net regional drying or moistening of the subtropical free troposphere by cross-isentropic motions is primarily balanced by isentropic transport of water vapor, which redistributes water vapor within the subtropics and moderates relative humidity contrasts. That is, the isentropic transport of water vapor is predominantly downgradient, albeit not necessarily diffusive (Pierrehumbert et al. 2007; O'Gorman and Schneider 2006). Thus isentropic fluxes of water vapor moisten dry subtropical regions (e.g., the dry oceanic regions in the summer hemisphere), similar to what was proposed by Emanuel and Pierrehumbert (1995), Salathé and Hartman (1997), Pierrehumbert (1998), Pierrehumbert and Roca (1998); they dry moist subtropical regions (e.g., the moist continental regions in the summer hemisphere), similar to what was proposed by Kelly et al. (1991), Yang and Pierrehumbert (1994), and Galewsky et al. (2005); however, unlike what was proposed in several earlier studies, they do not lead to substantial net import or export of water vapor into or out of the subtropics in the zonal mean.

Overall, our results show that the relative humidity of the subtropical free troposphere is maintained by a balance of large-scale processes (e.g., radiative subsidence) and smaller-scale processes (e.g., convection 
over continents or in fronts in intrusions of extratropical cyclones into low latitudes), with strong zonal inhomogeneities in their relative importance. As the climate changes, there is no obvious reason to assume that the moistening or drying by these different processes would change in proportion to each other, so there is no reason to assume that, on geological time scales, the relative humidity in the subtropical free troposphere cannot change substantially with climate, potentially leading to strong radiative feedbacks (Pierrehumbert 1999). The relative humidity of the free troposphere is not directly constrained by the surface energy balance, unlike the near-surface relative humidity (Boer 1993; Held and Soden 2000; Schneider et al. 2009). Indeed, in simulations of twenty-first-century climate change scenarios, the relative humidity in the subtropical free troposphere does change more strongly than that near the surface, albeit still by up to only $\sim 4$ percentage points (e.g., Yao and Del Genio 1999; Lorenz and DeWeaver 2007). It changes more substantially (by $\sim 10-20$ percentage points) in simulations of a wide range of climates with an idealized GCM, spanning global-mean surface temperatures from 259 to $316 \mathrm{~K}$ (O'Gorman and Schneider 2008). The multitude of processes apparently involved makes it a challenge to devise theories of how the relative humidity of the subtropical free troposphere is maintained in the mean and how it may change with climate.

Acknowledgments. A. Couhert and T. Schneider gratefully acknowledge support by the National Science Foundation (Grant ATM-0450059) and a David and Lucile Packard Fellowship. J. Li and D. Waliser were supported by the Jet Propulsion Laboratory, California Institute of Technology, under a contract with the National Aeronautics and Space Administration. We thank Anthony Del Genio and Adam Sobel for helpful comments and discussions.

\section{APPENDIX}

\section{Data Processing Methods}

\section{a. Full-level pressures in hybrid coordinates}

The IFS model employs hybrid vertical coordinates that make a continuous transition from sigma coordinates near the surface to pressure coordinates at upper levels (Simmons and Burridge 1981). There are 60 "full" levels, on which the fields we use are given, and 61 "half" levels. The pressure on full levels, needed for the calculation of potential temperatures, is not directly available, but that on half level $k(0 \leq k \leq 60)$ is given by

$$
p_{k+1 / 2}(\lambda, \phi, t)=a_{k+1 / 2}+b_{k+1 / 2} p_{s}(\lambda, \phi, t),
$$

where $\phi$ is latitude, $\lambda$ is longitude, and $a_{k+1 / 2}$ and $b_{k+1 / 2}$ are given constants that define the vertical coordinate (ECMWF 2007). From these half-level pressures, we calculated the full-level pressures following Simmons and Burridge (1981) as

$$
\begin{aligned}
& p_{1}=\frac{p_{3 / 2}-p_{1 / 2}}{2} \\
& p_{k}=\frac{p_{k+1 / 2}-p_{k-1 / 2}}{\ln \left(p_{k+1 / 2} / p_{k-1 / 2}\right)}, \quad 1<k \leq 60 .
\end{aligned}
$$

\section{b. Interpolation to isentropic coordinates}

We interpolated full-level fields to 50 isentropic levels corresponding to potential temperatures ranging from 210 to 360 K. Following Juckes et al. (1994), we constructed equally spaced isentropic levels in the transformed potential temperature coordinate $\theta^{-1 / \kappa}$ to obtain isentropic levels that would be equally spaced in pressure in an isothermal dry atmosphere. We interpolated the flow fields to isentropic levels in such a way that vertical integrals over potential temperature of quantities weighted by the isentropic density are equal to massweighted integrals over height; see Schneider et al. (2006) for details.

\section{REFERENCES}

Andersson, E., and Coauthors, 2005: Assimilation and modeling of the atmospheric hydrological cycle in the ECMWF forecasting system. Bull. Amer. Meteor. Soc., 86, 387-402.

— , and Coauthors, 2007: Analysis and forecast impact of the main humidity observing systems. Quart. J. Roy. Meteor. Soc., 133, 1473-1485.

Boer, G. J., 1993: Climate change and the regulation of the surface moisture and energy budgets. Climate Dyn., 8, 225-239.

Courtier, P., J.-N. Thépaut, and A. Hollingsworth, 1994: A strategy for operational implementation of 4D-Var, using an incremental approach. Quart. J. Roy. Meteor. Soc., 120, 1367-1387.

Dessler, A. E., and K. Minschwaner, 2007: An analysis of the regulation of tropical tropospheric water vapor. J. Geophys. Res., 112, D10120, doi:10.1029/2006JD007683.

ECMWF, 2007: IFS documentation Cy31r1. Tech. Rep., European Centre for Medium-Range Weather Forecasts, 950 pp. [Available online at http://www.ecmwf.int/research/ifsdocs/CY31r1/.]

Emanuel, K. A., and R. T. Pierrehumbert, 1995: Microphysical and dynamical control of tropospheric water vapor. Clouds, Chemistry, and Climate, P. J. Crutzen and V. Ramanathan, Eds., NATO ASI Series I, Vol. 35, Springer, 17-28.

Galewsky, J., A. Sobel, and I. Held, 2005: Diagnosis of subtropical humidity dynamics using tracers of last saturation. J. Atmos. Sci., 62, 3353-3367.

Held, I. M., and B. J. Soden, 2000: Water vapor feedback and global warming. Annu. Rev. Energy Environ., 25, 441-475.

Hólm, E., E. Andersson, A. Beljaars, P. Lopez, J.-F. Mahfouf, A. Simmons, and J.-N. Thépaut, 2002: Assimilation and 
modelling of the hydrological cycle: ECMWF's status and plans. ECMWF Tech. Memo. 383, 55 pp.

Juckes, M. N., I. N. James, and M. Blackburn, 1994: The influence of Antarctica on the momentum budget of the southern extratropics. Quart. J. Roy. Meteor. Soc., 120, 1017-1044.

Kelly, K. K., A. F. Tuck, and T. Davies, 1991: Wintertime asymmetry of upper tropospheric water between the northern and southern hemispheres. Nature, 353, 244-247.

Lorenz, D. J., and E. T. DeWeaver, 2007: The response of the extratropical hydrological cycle to global warming. J. Climate, 20, 3470-3484.

Lorenz, E. N., 1955: Available potential energy and the maintenance of the general circulation. Tellus, 7, 157-167.

Luo, Z., and W. B. Rossow, 2004: Characterizing tropical cirrus life cycle, evolution, and interaction with upper-tropospheric water vapor using Lagrangian trajectory analysis of satellite observations. J. Climate, 17, 4541-4563.

Mitas, C. M., and A. Clement, 2005: Has the Hadley cell been strengthening in recent decades? Geophys. Res. Lett., 32, L03809, doi:10.1029/2004GL021765.

Newell, R. E., N. E. Newell, Y. Zhu, and C. Scott, 1992: Tropospheric rivers?-A pilot study. Geophys. Res. Lett., 19, 2401-2404.

O'Gorman, P. A., and T. Schneider, 2006: Stochastic models for the kinematics of moisture transport and condensation in homogeneous turbulent flows. J. Atmos. Sci., 63, 2992-3005.

— and - 2008: The hydrological cycle over a wide range of climates simulated with an idealized GCM. J. Climate, 21, 3815-3832.

Peixoto, J. P., and A. H. Oort, 1996: The climatology of relative humidity in the atmosphere. J. Climate, 9, 3443-3463.

Pierrehumbert, R. T., 1998: Lateral mixing as a source of subtropical water vapor. Geophys. Res. Lett., 25, 151-154.

_ 1999: Subtropical water vapor as a mediator of rapid global climate change. Mechanisms of Global Change at Millennial Time Scales, Geophys. Monogr., Vol. 112, Amer. Geophys. Union, 339-361.

_- and R. Roca, 1998: Evidence for control of Atlantic subtropical humidity by large scale advection. Geophys. Res. Lett., 25, 4537-4540.

- H. Brogniez, and R. Roca, 2007: On the relative humidity of the atmosphere. The Global Circulation of the Atmosphere, T. Schneider and A. H. Sobel, Eds., Princeton University Press, 143-185.

Riehl, H., and J. S. Malkus, 1958: On the heat balance in the equatorial trough zone. Geophysica, 6, 503-538.

Ryoo, J.-M., T. Igusa, and D. W. Waugh, 2009: PDFs of tropical tropospheric humidity: Measurements and theory. J. Climate, 22, 3357-3373.

Salathé, E. P., Jr., and D. L. Hartman, 1997: A trajectory analysis of tropical upper-tropospheric moisture and convection. J. Climate, 10, 2533-2547.

Schneider, T., 2005: Zonal momentum balance, potential vorticity dynamics, and mass fluxes on near-surface isentropes. $J$. Atmos. Sci., 62, 1884-1900.

— K. L. Smith, P. A. O'Gorman, and C. C. Walker, 2006: A climatology of tropospheric zonal-mean water vapor fields and fluxes in isentropic coordinates. J. Climate, 19, 59185933.

, P. A. O'Gorman, and X. Levine, 2009: Water vapor and the dynamics of climate changes. Rev. Geophys., in press.

Sherwood, S. C., 1996a: Maintenance of the free-tropospheric tropical water vapor distribution. Part I: Clear regime budget. J. Climate, 9, 2903-2918.

_ 1996b: Maintenance of the free-tropospheric tropical water vapor distribution. Part II: Simulation by large-scale advection. J. Climate, 9, 2919-2934.

— relative humidity. J. Climate, 19, 6278-6290.

Simmons, A. J., and D. M. Burridge, 1981: An energy and angularmomentum conserving vertical finite-difference scheme and hybrid vertical coordinates. Mon. Wea. Rev., 109, 758-766.

_ _ A. Untch, C. Jakob, P. Kållberg, and P. Undén, 1999: Stratospheric water vapour and tropical tropopause temperatures in ECMWF analyses and multi-year simulations. Quart. J. Roy. Meteor. Soc., 125, 353-386.

Sun, D.-Z., and R. S. Lindzen, 1993: Distribution of tropical tropospheric water vapor. J. Atmos. Sci., 50, 1643-1660.

Tiedtke, M., 1989: A comprehensive mass flux scheme for cumulus parameterization in large-scale models. Mon. Wea. Rev., 117, 1779-1800.

_ 1993: Representation of clouds in large-scale models. Mon. Wea. Rev., 121, 3040-3061.

Tompkins, A. M., and Coauthors, 2004: Moist physical processes in the IFS: Progress and plans. Tech. Rep. 452, European Centre for Medium-Range Weather Forecasts, 93 pp. [Available online at http://www.ecmwf.int/publications/library/ecpublications/_pdf/ $\mathrm{tm} / 401-500 / \mathrm{tm} 452$.pdf.]

— K. Kierens, and G. Rädel, 2007: Ice supersaturation in the ECMWF integrated forecast system. Quart. J. Roy. Meteor. Soc., 133, 53-63.

Uppala, S. M., and Coauthors, 2005: The ERA-40 Re-Analysis. Quart. J. Roy. Meteor. Soc., 131, 2961-3012.

Waliser, D. E., and Coauthors, 2009: Cloud ice: A climate model challenge with signs and expectations of progress. J. Geophys. Res., 114, D00A21, doi:10.1029/2008JD010015.

Waugh, D. W., 2005: Impact of potential vorticity intrusions on subtropical upper tropospheric humidity. J. Geophys. Res., 110, D11305, doi:10.1029/2004JD005664.

Wright, J. S., A. H. Sobel, and G. A. Schmidt, 2009: Influence of condensate evaporation on water vapor and its stable isotopes in a GCM. Geophys. Res. Lett., 36, L12804, doi:10.1029/ 2009GL038091.

Yanai, M., S. Esbensen, and J.-H. Chu, 1973: Determination of bulk properties of tropical cloud clusters from large-scale heat and moisture budgets. J. Atmos. Sci., 30, 611-627.

Yang, H., and R. T. Pierrehumbert, 1994: Production of dry air by isentropic mixing. J. Atmos. Sci., 51, 3437-3454.

Yao, M. S., and A. D. Del Genio, 1999: Effects of cloud parameterization on the simulation of climate changes in the GISS GCM. J. Climate, 12, 761-779.

Zhu, Y., and R. E. Newell, 1998: A proposed algorithm for moisture fluxes from atmospheric rivers. Mon. Wea. Rev., 126, 725-735. 